\title{
Tamil Siddha Yoga Philosophy on Conception- Garba Kriya from Thirumoolar's Thirumandiram
}

\author{
Geetha Anand* \\ Research Scholar, Tamil Siddha Philosophy, India
}

Submission: January 24, 2018; Published: February 08, 2018

*Corresponding author: Geetha Anand, Research Scholar, Tamil Siddha Philosophy, India, Email: geethaa@yahoo.com

\section{Introduction}

The concept of gender selection has been in vogue for many years. Sill et al. [1] mention that references to gender selection are found in texts as ancient as the Old Testament and that Egyptians had important insights into male reproductive function. In many cultures male offspring are preferred to carry the family name, inherit property and to support the parents in old age. The topic of gender selection has attracted a lot of attention currently as well for the moral and ethical concerns associated with it. Some argue that gender selection is an expression of a woman's reproductive right, that it is a way to prevent unintended pregnancy and abortion and to avoid child neglect. However, those who oppose it argue that it is not correct for people to play "god" and tailor-make the child of their choice.

The Ethics committee of American Society of Reproductive Medicine supports gender selection to avoid birth of an offspring with congenital chromosome-linked disorders. With the advent of sperm sorting techniques that utilize flow cytometric method to separate and enrich sperms selectively for the $\mathrm{X}$ or Y chromosome, gender selection has become technically easy to practice. (The) Sperms with (selected) specific chromosomes are implanted in the womb and the success ratein this technique has been around 75-80\%. Preimplantation Genetic diagnosis where the embryos are tested before they are implanted in the womb is promoted as the method of choice to avoid congenital diseases. The success rate in this method is almost 100 percent.

While gender selection is technically possible, it is not the method of choice for many. Chromosomal selection procedure is expensive costing around $\$ 20,000$ for the sorting alone. Selective implantation is not possible if there is a limitation on the number of eggs available for fertilization. Gender selection may also cause psychological impact at a later time

when something goes wrong with the offspring such as a disease or a physical disability. This paper aims to put forth Tamil Siddha Thirumoolar's ideas on successful conception and having a healthy offspring of choice. As these methods are only recommendations for influencing the nature of the offspring, the moral and ethical dilemmas that couples face in the chromosomal selection procedure do not arise here.

Siddha Thirumoolar's work Thirumandiram is considered a flagship composition on Tamil Siddha yoga. While the date of Thirumoolar cannot be established unequivocally, as is common with the Tamil Siddhas, Ganapathy [2,3] feels that Thirumoolar must have lived between the fifth and sixth century. Thirumandiram describes both, spiritual as well as worldly concepts in nine tantirams. Suffice to say that Thirumoolar's description of the process of conception agrees well with modern day scientific knowledge.

In tantiram 2 section 14 titled Karpakiriyai (Garba Kriya) Thirumoolar elaborates on the birth process through 41 verses. He begins the section with the comment that a man and a woman attempt physical union to express their love. The primal Lord uses the event to bring together the necessary principles that would result in a life form. The twenty five principles- five senses of knowledge, five senses of action, their five actions, the five elements and their five subtle qualities, are brought together to create the garbakolagai or the sphere of conception. Thirumoolar is thus referring to the materials inside the sperm that would cause conception. The twenty five principles mentioned above are first placed in the man's body. They are transferred to the woman's body during physical union. Thirumoolar describes the site of the womb as that which is above the muladhara and where the agnior fire principle and appu or water principle remain. The fetus grows for ten months in the womb before its release into the world. When the linga or the male reproductive organ falls into the yoni or the female reproductive organ the fifteen principlesthe ten senses and the five elements, enter the womb through the sexual fluid. They hide at the brow middle and at the top of the head of the fetus. The fetus emerges as the life form if the Lord brings together the eight principles that constitute the subtle body(touch, taste, form, sound, fragrance, intellect, mind and 
egoity), the ten senses (five senses of knowledge and five senses of action), the five elements (space, air, fire, water and earth), the three energy channels (ida, pingala and sushumnanadi), the soul, the nine gateways or energy centers and kundalini sakthi (which remains in the body as heat) together. Otherwise it is not a live birth. Thus, unless the Lord attaches the subtle elements to the soul it does not become alive. The subtle five sheaths orpanchakosha are attached to the body according to the karma of the soul. The fetus remains without breathing. When vayu or air principle enters the body, it starts to cry for the first time.

During conception, the sperm meets the nadha or the primordial creative force of the woman. Thirumoolar says that if they meet in such a way that there is enhancement, then the fetus has the nature of Rudra. If they meet opposing each other, the fetus takes the quality of Vishnu and if they meet with equivalent force then the fetus has the qualities of Brahma. In Siddha parlance these deities represent states with varying number of innate impurities or mala. Mala influence the attitude of a person, his outlook, his way of life. Anava, karma, maya, mayeya (product of maya) and tirodhayi (concealing power) are the five types of mala. Rudra is under the influence of anava, karma and maya only. He is free of mayeya and tirodhayi. So, a person born with Rudra-like qualities will see the true nature of things easily. He will not be deluded by the evolutes of maya. Vishnu is under the influence of four of the five mala while Brahma has all the five mala and is hence totally controlled by the mala. Thus, the pattern of physical union decides the attitude and the power of perception of the offspring.

Thirumoolar describes how the temperature of the fetus is maintained in the womb. He says that the two nadi, ida and pingala, run through the body in parallel and in harmony. They keep the fetus at the right temperature so that it is not burnt by the fire in the muladhara. The nadis are not present in the gross body. They are energy channels present in the subtle body. Tamil Siddhas claim that the nadis are not permanent structures. They emerge based on a person's state of existence. Thus, the nadis mentioned here may be those of the mother or the fetus as the subtle body of the fetus is created before the gross body. Thirumoolar says that the Lord adds more protection to the fetus from the fire in the muladhara by creating several whorls. The whorl mentioned here refers to the chakra in the subtle body. The chakras regulate various principles in the body including the action of the five elements. Tirumoolar recommends that the man and the woman engaged in the union should be in a calm state of mind if they wish that the union would produce an offspring. He says that when the male and the female fluids meet, the breath should be eight measure inhalation and twelve measure exhalation. This is the normal breathing pattern when a person is calm.

According to Thirumoolar the soul does not have a gender. Distinctions such as male and female are present only at the physical level. It is actually the fire of kundalini that grows as a lifeform. However, whether the gross form of the offspring is maleor female depends on which factor is more. If the male factor is more, then the offspring will be male and if the female factor is more it will be female. If both the factors are equal, then the fetus will be of neuter gender. This concept is similar to modern day science which states that the male factor, $\mathrm{Y}$ chromosome will confer masculine gender, the female factor $\mathrm{X}$ chromosome will confer feminine gender and situations like XXXY chromosomal pattern confer a male with female characteristics (Klinefelter syndrome) and vice versa.

Thirumoolar has recommendations for influencing the lifespan of the offspring. He says that after the union "if the five flow" the lifespan will be hundred, "if four flow" it will be eighty. He adds further that only a yogin can control the vayu's flow and make it travel as desired. Some commentators feel that the five and the four may be the number of breaths up to which time the couple should remain together after the release. In modern scientific terms this would ensure that the sperm gets enough time cross the mucus membrane and reach the womb. Five and four may also means that if the semen flows for five finger spans and falls into the egg, the life span will be hundred and if it flows for four finger spans it is eighty years. Traveling a greater distance would ensure that the sperm will reach the womb without getting trapped on the way. This would also ensure that all the necessary materials are transferred from the sperm so that the fetus is healthy and there are no deficiencies. Five and four may refer to the speed of the sperm when it enters the female reproductive machinery. Shulman [4] and coworkers point out that sperm motility plays a great role in successful pregnancy. Another interpretation that the five may be the five vital breaths or pancha prana namely prana, apana, vyana, samana and udhana in the man. When all the five flow it means the man's body and his semen are healthy. Any decrease in their number means to a deficiency or a disability in the body. This explanation seems more plausible as the next verse talks about the speed of the vayu that drives the sperm inside the womb. Thirumoolar says that if the amount of the vayuor air principle that drives the sperm inside the womb is low, then the offspring will be short in stature. If the flow is faint or feeble, then the offspring will have disabilities in its limbs. If the flow is inhibited the offspring will have a hunch. This rule applies to vayu present in the man only and not in the woman. In the case of the woman, if the feces has not been cleared to the required amount before the union the offspring will be a dullard. If there is urine, then the child will lack the power of speech. If both are present in equal amount, then it will be blind.

Thirumoolar's comment about gender selection is interesting. He says that if the prana of the man flows in the right nostril during the union the offspring will be male, if it flows in the left nostril it will be female and if it flows equally in both nostrils it will be of neuter gender. When prana is opposed by apana which goes up, then there will be twin birth. If the prana 
rises in harmony in both, the man and the woman, then the offspring will be beautiful. If the breath falters there will be no conception. Thus, the breath of both the partners is important to have a beautiful child. Thirumoolar may mean that the couple should have mental harmony during copulation as the pattern of their breath depends on their state of mind.

Thirumoolar states that the fetus in the womb grows into a beautiful form, nourished by a golden inner light. This refers to the subtle energies that contribute to the features of the child. He concludes this section stating that even though the seed for the child is provided by the man and nurtured by the woman they do not know the subtle energies of maya that influence the offspring. He adds that just as how the water of the ocean collects, evaporates and forms salt, all the life forms emerge from the ocean of consciousness and redissolve in it, due to divine grace. Tamil Siddhas are well known for their philosophical theories and medical practices. Even today Siddha Agastya's medical preparations are used to treat chronic diseases such as diabetes, cancer and renal failure. While the methods recommended by Thirumoolar here have not been tested scientifically for their validity they offer a venue for couples who cannot utilize the modern in vitro fertilization techniques. Thirumoolar states that a yogin will be able to control all the factors mentioned above and have a desired offspring. Hence, it is worth studying the role of pranayama and other yogic practices on gender selection and the nature of the offspring in a scientific manner. These techniques offer a gentle and cost-effective methods that could be practiced easily with some guidance if one desires an offspring with a specific gender or qualities for any reason.

\section{References}

1. Sillis ES, Kirman I, Thatcher SS, Palermo GD (1998) Sex-selection of human spermatozoa: evolution of current techniques and applications. Arch Gynecol Obstet 261(3): 109-115.

2. Ganapathy TN, Arumugam KR, Geetha A (2004) Introduction. In the Yoga of Siddha Tirumular, Babaji's Kriya Yoga and Publications, Inc, Canada, pp. 27-32.

3. Ganapathy TN (2010) English translation of the Tirumandiram. Yoga Siddha Research Center Publications, Babaji's Kriya Yoga and Publications, Canada, pp. 541-581.

4. Shulman A, Hauser R, Lipitz S, Frenkel Y, Dor J, et al. (1998) Sperm motility is a major determinant of pregnancy outcome following intrauterine insemination. J Assit Reprod Genet 15(6): 381-385.

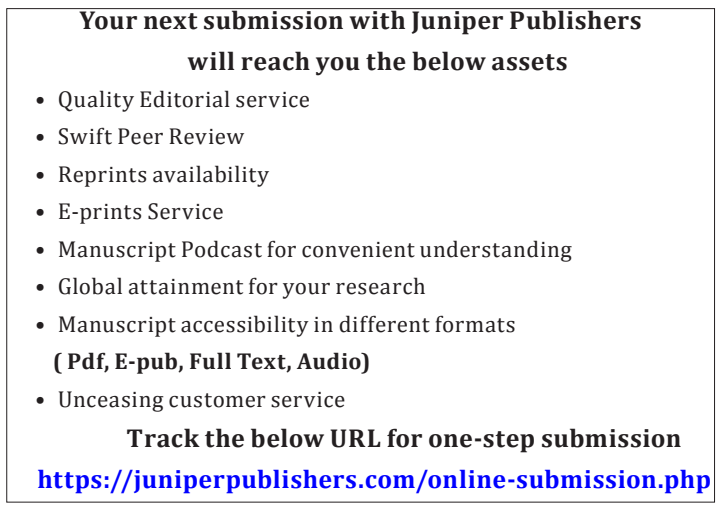

